\title{
Inhalt
}

Vorwort ........................ VII

AufsëtZe

Carola Groppe

Freundschaften mit Auftrag und Gefährdung:

Im George-Kreis . . . . . . . . . . . . . . . .

Kai Kauffmann

,Soll nun der mund sich klagend öffnen'?

Dichtung als Kommunikationsmedium im Verhältnis zwischen

George und Hofmannsthal . . . . . . . . . . ... 27

Jörg Schuster

,Lebendige Schrift‘? Medium, Inspiration und Kollaboration

bei Stefan George, Hugo von Hofmannsthal und Harry

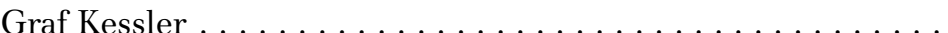

\section{Cornelia Ortlieb}

Verbundene im neuen Land. George, Hofmannsthal

und der europäische Symbolismus . . . . . . . . . . .

Kay Ehling

,Purpurnes weinlaub im haare ${ }^{6}$ - Eine biographische Notiz

zu Stefan George als Weintrinker ...............

DOKUMENTATION

Wolfgang Braungart

Stefan George: Leben, Werk, Forschung . . . . . . . . . . . . . . 113

Jan Andres

Das Castrum Peregrini und der George-Kreis -

eine Differenzierung . . . . . . . . . . . . . . . 
Kai Kauffmann

Worüber reden wir im Falle von Stefan George eigentlich:

über Homosexualität, über Päderastie, über Pädophilie,

über sexuellen Missbrauch oder über sexualisierte Dichtkunst? .

\section{Rezensionen}

Stefan George: „Von Kultur und Göttern reden“.

Aus dem Nachlass. Ergänzungen zu Georges

„Sämtlichen Werken“. Im Auftrag der Stefan George Stiftung

hg. von Ute Oelmann (Jørgen Sneis) . . . . . . . . . . . . . .

Jürgen Egyptien (Hg.): Stefan George - Werkkommentar (Jan Andres) . . . . . . . . . . . . . . . . . . . . . .

Franziska Walter: Meisterhaftes Übersetzen.

Stefan Georges Übersetzung der Sonette Shakespeares

(Gabriele von Bassermann-Jordan). . . . . . . . . . . . . . .

Thomas Karlauf: Porträt eines Attentäters

(Gunilla Eschenbach).. . . . . . . . . . . . . . . . . .

Aus der Stefan-George-Gesellschaft

Gabriele von Bassermann-Jordan

Nachrichten . . . . . . . . . . . . . . . . . . . . . . . . .

Kai Kauffmann

Nachruf auf Prof. Dr. Bernhard Böschenstein . . . . . . . . . . . 167

Stefan-George-Gesellschaft e.V. Bingen . . . . . . . . . . . . . . 169

Anschriften der Beiträgerinnen und Beiträger . . . . . . . . . . . . 172 